\title{
Estudo dos motivos para o fracasso dos estudantes e professores na relação ensino-aprendizagem de química do ensino médio
}

DOI: $10.46814 / \operatorname{lajdv} 3 \mathrm{n} 3-032$

Recebimento dos originais: 01/052021

Aceitação para publicação: 31/06/2021

\author{
João Roberto Fortes Mazzei \\ Doutor em Ciências e Engenharia do Meio Ambiente \\ Instituição de atuação atual: Universidade Federal do Rio de Janeiro; UFRJ \\ Endereço: Av. Athos da Silveira Ramos, 149 - Edifício do Centro de Tecnologia - Bloco A - $2^{\circ}$ \\ andar - Cidade Universitária - Rio de Janeiro - RJ - \\ Email: bymazzei@poli.ufrj.br ; bymazzei@gmail.com
}

\section{RESUMO}

O presente trabalho realizou estudo sobre o fracasso dos estudantes e professores no aprendizado do ensino da disciplina Química no ensino médio das escolas públicas, auxiliando na estruturação de estratégias pedagógicas para o abismo que há entre o que é ensinado, o que é aprendido e o que tem aplicabilidade na vida cotidiana dos estudantes desta ciência nas escolas. O trabalho foi realizado no Colégio Pedro II, campus São Cristóvão III e consistiu na construção de mapas conceituais por 52 alunos do ensino médio, primeira e segunda séries, reprovados em Química. Com base nas teorias sobre a aprendizagem significativa proposta Ausubel, visou-se trazer uma reflexão sobre o porquê do fracasso de alunos e professores no aprendizado da disciplina Química devido à falta de aprendizagem significativa. Com o resultado da pesquisa foram feitas propostas de norteadores aos professores, a fim de tornarem suas aulas mais pertinentes ao universo do aluno e mais estimulantes ao aprendizado. Espera-se que esse trabalho contribua para tornar as aulas de Química mais agradáveis e atraentes, norteando métodos para registro das observações que possam ser comprovadas por dados experimentais. Dessa forma, pretende-se de tecer reflexões para que sejam repensados o currículo e a práxis na sala de aula. Além de fomentar nos alunos, o espírito investigativo e de pesquisa para responder a hipóteses problematizadoras no âmbito da disciplina Química, trazendo aplicabilidade dos conteúdos absorvidos em sala de aula e, sobretudo, que se relacionem ao cotidiano de suas atividades. Espera-se que este trabalho ajude o professor a capacitar seu aluno a desenvolver interesse pelos estudos da ciência.

Palavras-chave: Fracasso escolar; aprendizagem significativa; mapas conceituais; David Ausubel.

\section{INTRODUÇÃO}

Em diversos artigos publicados sobre o ensino da química, observa-se que os "referenciais teóricos" - principalmente os que surgem a partir de teorias de cálculos, parecem não representar nada além de mais um "paper” rotineiro, ou fazerem menção a uma ciência abstrata e, portanto, inatingível e afastada do cotidiano do estudante. (POLITO \& COELHO, 2018, p. 2-3).

Historicamente, o insucesso nos estudos da Química faz com que essa ciência seja vista como vilã para os estudantes do ensino médio (ANGELUCCI et al, 2004) 
(...) O fracasso na escola pode ser entendido sobre quatro fatores: psíquico, técnico, institucional e político.

Estes fatores podem influenciar da seguinte maneira, segundo os autores:

1) Psíquico - Neste aspecto, os prejuízos com a aprendizagem são atribuídos ao aluno e a falta de ambientação é atribuída ao estudante a responsabilidade pelo insucesso estudantil e pressupõe-se a escola como ambiente ideal em que as coisas transcorrem sem problemas.

2) Técnico - Neste aspecto, o fracasso escolar é visto como se fosse gerado na e pela escola. Desta forma, muito do insucesso da aprendizagem é atribuído à falta de técnica do professor e todos os questionamentos se voltam para a velha máxima: a formação do professor e a desconexão entre os conteúdos ofertados pelos mesmos durante as aulas com a realidade do estudante.

3) Institucional - Nesta visão, o fracasso dos estudos é atribuído às instituições das redes públicas ou privadas de ensino. Surge uma crítica muito forte com relação ao descaso e descompromisso destas instituições coma uma política educacional que seja focada em um processo de democratização do ensino, e que não torne educação excludente aos alunos, comunidade e até à família - Escola sem muros ou fronteiras.

4) Político - Esse talvez seja o mais delicado dos fatores.

Segundo Angelucci et al., (2004):

(...) o fracasso escolar pode ser uma maneira equivocada de rotular e problematizar um processo legítimo de reivindicação da transformação da estrutura educacional. Desta forma, há uma Desta forma há uma ampliação nas relações causais que determinam a presença do fracasso escolar, não cabendo apenas a participação popular no processo educativo, mas a abertura da cultura dominante escolar para a cultura popular

A falta de aplicabilidade dos conteúdos da Química e a sua dissociação da realidade dos alunos dificulta a aprendizagem, pois, torna esta ciência desinteressante e sem explicação do porquê estudála, trazendo sérios atrasos à relação ensino / aprendizagem.

Muito cuidado deve ser tomado na escolha do método científico, a escolha não pode ser realizada de forma deliberadamente intuitiva. Há três tipos principais de métodos: os inventivos; os sistemáticos e os didáticos.

O método inventivo e o sistemático pertencem à lógica e os didáticos, à pedagogia.

A lógica e a pedagogia tornam-se aliadas na busca pela metodologia ideal para cada pesquisa e podem traduzir em ganho ou perda do saber as metodologias aplicadas.

Uma grande ferramenta de organização dos trabalhos aliada à metodologia são os mapas conceituais. Estes mapas reúnem dados que partem das ideias iniciais (formulação da hipótese), passam 
pelos estágios evolutivos, anotando as dúvidas e questionamentos surgidos ao longo do experimento e mostram as conclusões que o mesmo gerou como hipótese científica.

Segundo Moreira (2018 p. 137):

(...) Os organizadores prévios podem tanto fornecer "ideias-âncora" relevantes para a aprendizagem significativa do novo material, quanto estabelecer relações entre ideias, proposições e conceitos já existentes na estrutura cognitiva e aqueles contidos no material de aprendizagem.

A correlação entre o espírito da metodologia científica e a sala de aula deve ser buscada, a fim de trazer aplicabilidade aos conteúdos já conseguidos. Na organização dos métodos, precisamos saber fazer distinção entre organizadores e pseudo-organizadores prévios. Para Ausubel (1980), organizadores prévios verdadeiros são aqueles destinados a facilitar a aprendizagem significativa de tópicos específicos, ou série de ideias estreitamente relacionadas. Os materiais utilizados para facilitar a aprendizagem de vários tópicos denominam-se pseudo-organizadores prévios.

Estudos de Lemos (2013) ressaltam que a avaliação da aprendizagem significativa é pouco levada à discussão nos cursos de formação de professores, e que isso trava a aprendizagem na prática de sala de aula, podendo ser um dos fatores que justificam o fracasso escolar, sobretudo na disciplina Química.

\section{O FRACASSO ESCOLAR}

Segundo Bossa (2002), a preocupação com o fracasso na escola emerge com a obrigatoriedade da escola, no século XIX, devido às transformações sociais da época. Pode ser considerado como patologia, por alguns pesquisadores do sistema educacional e foi sendo esculpida a partir da escolaridade obrigatória, proposta ao final do século XX, passando a ocupar significativo lugar nas mentes e como estudo do comportamento, em detrimento às mudanças de comportamento radicais da sociedade.

Não apenas a exigência da sociedade com relação ao "letramento", mas a importância em termos do poder do capital, sucesso e ascensão social, estão relacionados ao bom sucedimento escolar. Esta exigência da sociedade causa os distúrbios que acabam por acarretar em um mal rendimento escolar.

De uma forma ou de outra a história de cada indivíduo têm um reflexo das pressões sociais exercidas em função de um bom rendimento escolar.

Segundo (CORDIÉ, 1996, p.22):

(...) Buscam-se compreender as condições que possibilitam uma forma de subjetividade que produz esse sintoma culturalmente determinado de modo a repensar sobre os fatores 
implicados no fracasso escolar, aspecto sócio-cultural, conflitos familiares, sistemas pedagógicos, deficiência intelectual.

O fracasso escolar também não pode nem deve ser atribuído somente ao aluno, segundo as opiniões de (WEISS, 2007, p.16),

“[...] Há todo um universo ao redor que implica em estar atento também a outras perspectivas que possibilitem este estudo, sendo elas a escola, a sociedade e também o aluno”.

A autora atribui o fracasso escolar como sendo uma resposta negativa do aluno frente às obrigações e exigências impostas pela escola.

$\mathrm{Na}$ e avaliação do fracasso escolar de um aluno não se pode desconsiderar as relações existentes entre o que a escola produz e as experiências, positivas e negativas, que a sociedade oferece aos indivíduos das classes sociais, e que os estudantes das escolas públicas oriundos das classes mais baixas da pirâmide social, e portanto, de baixa renda da população são, normalmente, inseridos em "classes escolares especiais", encaixados no grupo de possíveis "deficientes mentais", aqueles que apresentam dificuldades cognitivas sérias e problemas de aprendizagem.

A pobreza dos alunos figura como um dos causadores da dificuldade de aprendizagem. Contudo, alerta que, mesmo sendo demonstrado que muitas vezes o fracasso dos alunos esteja relacionado a pobreza material, falta de material didático e má alimentação, é imprescindível que foquemos os olhares para o fato de que a baixa renda familiar não seja adotada como a única justificativa para este fracasso, excluindo assim a organização escolar (didático/pedagógica), bem como o sistema educacional, em âmbito geral, das responsabilidades por este insucesso (SCOZ, 1994).

\section{A VIDA ESCOLAR E A PARTICIPAÇÃO DA FAMÍLIA}

A influência da família no comportamento e na formação do aluno, gera reflexos imediatos na relação ensino/aprendizagem que este aluno vai agregar ao longo de sua vida escolar.

Sendo a família que o aluno participa e apresenta suas primeiras manifestações de valores culturais e emocionais, torna-se indiscutível a sua influência no caminhar de seus componentes.

A escola acaba por ser a responsável pela conexão entre este aluno e a sociedade, que hoje globalizada, toma um caráter muito mais amplo e universal.

A escola tem percebido o quanto a manutenção do interesse dos pais e familiares, quer indo à simples reuniões escolares, quer acompanhando as atividades propostas pela escola vê colhendo melhores frutos para o sucesso escolar. Em contrapartida, quando a família não tem uma boa relação familiar e há um desinteresse por parte dos pais ou familiares com relação às suas atividades escolares, 
a escola tem percebido uma baixa autoestima e em um rendimento escolar puxado para baixo. Ou seja, independente de como a família está estruturada social e economicamente, é fundamental o apoio ao estudante em suas atividades, pois a mesma participa e influencia ativamente no rendimento escolar desse aluno.

Estudos apontam para o fato de que quando a criança tem vínculos familiares sólidos e positivos, esses influenciarão de forma satisfatória na relação entre o aluno com a escola, professores e outros alunos. Pois, é na família que esse aluno aprende a reprimir seus instintos e a criar um perfil de conduta padrão com o qual irá seguir e reproduzir no desenvolvimento de seu papel social e nos seus valores de comportamento, ética e cidadania.

Segundo (BOCK, 1999):

(...) os pais também controlam explicitamente o comportamento de seus filhos para que eles tenham um desempenho considerado adequado em termos dos padrões sociais.

A escola tem percebido que os filhos de pais ausentes experimentam sentimentos de desvalorização, sendo mais inseguros, menos produtivos, e com pouco ou nenhum interesse pelos estudos, criando sérios obstáculos à aprendizagem escolar. A boa relação familiar pode potencializar fatores que interferem na aprendizagem e indicar horizontes mais eficientes para orientar o estudante. Dessa forma, é fundamental que a escola municie informações aos pais, para que se sensibilizem com relação à influência e o poder da família no progresso escolar de seus filhos.

\section{FRACASSO ESCOLAR: FAMÍLIA X ESCOLA}

A escola é a responsável pela ligação facilitada entre o aluno e a sociedade e por isso, é considerada, umas das mais importantes instituições sociais. A escola tem o papel de humanização do aluno, uma vez que promove a transmissão da cultura, da história e faz o aluno entender de onde veio e os rumos que a humanidade se direciona rumo ao futuro dos tempos. Com a escola a criança vai deixando de ser expectador e somente reprodutor dos adultos e passa a ser mais crítica, apoderando-se de modelos passados pela escola e exercendo o seu saber de forma mais independente.

O contexto histórico-econômico-social auxilia-nos a entender o porquê de a escola ter adquirido tanta importância nas sociedades e ter ampliado as suas atribuições, buscando democratizar-se (BOCK, 1999).

A escola é a instituição que funciona e é sustentada pela sociedade e muitas vezes, acaba por realizar o papel que a própria família, por estar de certa forma, dilacerada, deixa de cumprir. A partir deste princípio, surge a atividade mediadora entre o jovem e a sociedade. 
Por perceber que viver em sociedade é mais que aprendizados formais, tais como: ensinos de matemática, escritas e ciências, a escola volta-se para um convívio, mais humanizado e privilegia o coletivo, as ações em conjunto e o espírito de equipe, que acabam por ser exigência da vida moderna e sinal de sobrevivência nos mercados de trabalhos competitivos dos dias contemporâneos globalizados. Segundo (BOCK, 1999),

(...) a escola é a forma moderna de operar essa transmissão de técnicas e habilidades. Compreendidos os momentos históricos atravessados pela escola até constituir-se como a conhecemos hoje, nos deparamos com a caracterização e problemas contemporâneos.

A escola tem sido crescentemente pesquisada e tem virado tema de teses de inúmeras pósgraduações como esta que lhe é apresentada, não só no Brasil, mas em muitos países. Os resultados obtidos em tais pesquisas apontam para alarmantes dados de baixa qualidade educacional em vários países, expressa por problemas como indisciplina nas escolas, condições impróprias para o ensino escolar, despreparo dos professores, baixos níveis salariais que são agravados no Brasil por elevados números de desistência e repetência (MARIN,1998).

\section{FRACASSO ESCOLAR: FAMÍlIA, ESCOLA E A CONTRIBUIÇÃO DA PSICOPEDAGOGIA}

Um dos problemas educacionais mais estudados no Brasil é influência da família e da escola diante do fracasso do sistema ensino/aprendizagem. Esta discussão tem como princípio o preparo e atuação do professor e da escola de entender a relação professor-aluno. Além destas, a família e uma análise de diversos autores sobre as contribuições da psicopedagogia como forma de prevenir o fracasso escolar, são objetos de estudo de diagnóstico.

A escola não tem flexibilidade para trabalhar a diversidade de informações que a realidade cotidiana produz em cada indivíduo. Desta forma, o fracasso escolar poderia ser atacado e combatido, em primeira instância, com intervenções pedagógicas adequadas para cada realidade. Mas, o grande problema é a morosidade com que o sistema educacional se reposiciona para acompanhar as mudanças sociais ao seu redor.

O fracasso escolar não está na realidade social, ele é, sim, um indicador das diferentes realidades sociais que o sistema educacional deve valorizar e trabalhar para orientar caminhos em que este sistema deverá seguir.

Estudos têm mostrado que aspectos relacionados à família e a escola podem desencadear evolução substancial na aprendizagem formal e informal propiciando suporte para o aluno aprender. 
O poder público e a legislação nacional baseada na LDB (Lei das Diretrizes e Bases da Educação Brasileira, deixam claramente evidenciados os deveres da família para com a o processo educacional proposto pelo país.

Art. $4^{\circ}$ : É dever da família, da comunidade, da sociedade em geral e do poder público assegurar, com absoluta prioridade, a efetivação dos direitos referentes à saúde, à alimentação, à educação, ao esporte, ao lazer, à profissionalização, à cultura, à dignidade, ao respeito, à liberdade e a convivência familiar e comunitária.

Art. 55: Os pais ou responsáveis têm a obrigação de matricular seus filhos ou pupilos na rede regular de ensino.

A Política Nacional de Educação Especial adota, como uma de suas diretrizes gerais, o Incentivo a mecanismos que oportunizem a participação efetiva da família no desenvolvimento global do aluno e entre seus objetivos específicos buscar o envolvimento familiar e da comunidade no processo de desenvolvimento da personalidade do educando.

A Lei de Diretrizes e Bases da Educação (Lei 9394/96), em seus artigos $2^{\circ}$ e $6^{\circ}$, determina:

Art. $2^{\circ}$ : A educação, dever da família e do Estado, inspirada nos princípios de liberdade e nos ideais de solidariedade humana, tem por finalidade o pleno desenvolvimento do educando, seu preparo para o exercício da cidadania e sua qualificação para o trabalho.

Art. $6^{\circ}$ : É dever dos pais ou responsáveis efetuar a matrícula dos menores, a partir dos seis anos de idade, no ensino fundamental. (Redação dada pela Lei nº. 11.114, de 2005)

O Plano Nacional de Educação (aprovado pela Lei nº 10.172/2001) implementa, como uma de suas diretrizes, a implantação de conselhos escolares e outras formas de participação da comunidade escolar (composta também pela família) e local na melhoria do funcionamento das instituições de educação e na experenciação das oportunidades educativas e dos recursos pedagógicos.

O Ministério da Educação (MEC) instituiu a data de 24 de abril como o Dia Nacional da Família na Escola. Nesta data, as escolas deveriam convidar os familiares dos alunos para participar de suas atividades educativas, estimulando a participação dos responsáveis e evidenciando que quando os pais se envolvem na educação dos filhos, eles aprendem mais" (MEC 2015).

\section{A PSICOPEDAGOGIA DIANTE DO FRACASSO ESCOLAR}

A atuação dos pedagogos, que funcionam como orientadores educacionais nas escolas brasileiras é baseada em duas vertentes.

Segundo Fernández (1990):

(...) o fracasso escolar responde a duas ordens de causas que se encontram imbicadas na história do sujeito próprios da estrutura familiar e individual daquele que fracassa em aprender e próprios do sistema escolar, sendo estes últimos determinantes. E que é preciso não confundir 
os fracassos escolares com problemas de aprendizagem para poder intervir antes que sejam produzidos, pois, muitas vezes, um pode derivar do outro.

Bossa (2007, p. 21-22) diz que:

O objetivo de estudo da Psicopedagogia deve ser entendido a partir de dois enfoques: preventivo e terapêutico. O enfoque preventivo considera o objeto de estudo da Psicopedagogia o ser humano em desenvolvimento, enquanto educável. Seu objeto de estudo é a pessoa a ser educada, seus processos de desenvolvimento e as alterações de tais processos. Focaliza as possibilidades do aprender, num sentido amplo. Não deve se restringir a uma só agência como a escola, mas ir também à família e à comunidade. Poderá esclarecer, de forma mais ou menos sistemática, a professores, pais e administradores sobre as características das diferentes etapas do desenvolvimento, sobre o progresso nos processos de aprendizagem.

\section{JUSTIFICATIVA DESTE TRABALHO:}

Muitas coisas no ensino da Química sempre me angustiaram e me levaram a fazer este estudo. Uma delas é a desconexão que existe entre os conteúdos aplicados em sala de aula com a vida da sociedade em que o aluno está inserido. Como exemplo, cito conteúdos decorados e de cunho puramente mnemônico como as nomenclaturas e classificações dos compostos químicos baseada em regras ortodoxas e que não trazem aprendizagem significativa.

A justificativa deste trabalho é estudar em que ponto a ciência Química ao ser ministrada em sala de aula com suas regras, nomenclaturas e símbolos cheios de exceções totalmente desconectados da realidade do aluno, não utiliza os subsunçores de conteúdo que o estudante já traz consigo e desta forma, deixa de ser interessante para este estudante, passando a fazer parte daquela matriz curricular que só serve para o aluno "passar de ano" ao conseguir a nota mínima exigida pela instituição ou ser reprovado por uma disciplina da qual esse aprendiz nem sabe por que estudar e ainda pior, acabar por não observar a beleza dos conteúdos aprendidos correlacionados ao seu dia-a-dia. Tendo em vista que a ciência Química se torna atraente porque se mune de um aprendizado que tenta explicar os fatos já conhecidos pela sabedoria popular, mas que ainda não foram justificados por esta comunidade. Assim, é saber genuíno, o trazido pelas pesquisas e torna-se imprescindível para o avanço das ciências e o conhecimento do Universo desde as suas origens até os caminhos futuros que serão traçados pelo mesmo. Em síntese, justifico este trabalho como uma tentativa de desmembrar estes conhecimentos da teoria pura e trazer aplicabilidade aos mesmos, tendo em vista que a própria palavra ciência já significa conhecimento. Desta forma, a pesquisa deve ser relevante; o projeto deve indicar a sua importância social e científica, sendo a delimitação do tema de fundamental importância para o sucesso das investigações deste trabalho.

\section{FUNDAMENTAÇÃO TEÓRICA:}


Passeando pelas páginas do livro: A teoria da Aprendizagem Significativa e sua implementação em sala de aula de Moreira, Marco Antonio, editora UNB, comecei a me interessar pela pesquisa da relação entre a falta de aprendizagem significativa em nos estudos da Química e os motivos pelos quais números muitos elevados dos alunos fracassam nos estudos desta Ciência, ou seja, não entendem os conteúdos, se desinteressam pelos mesmos e acabam por serem reprovados na disciplina Química. Justifico esta pesquisa com a finalidade de atribuir significados aos conteúdos Químicos para entender os "porquês" desta ciência tão esclarecedora de tantos aspectos de ocorrência cotidiana dos estudantes ser considerada como uma vilã na Estrutura Curricular Nacional.

\subsection{APRENDIZAGEM SIGNIFICATIVA}

Com o interesse de observar como a mente humana absorve, transforma, armazena e faz uso de uma nova informação, Ausubel propôs uma nova teoria cognitiva, a aprendizagem significativa, que segundo sua visão:

"[...] é um processo por meio do qual uma nova informação se relaciona, de maneira substantiva (não literal) e não arbitrária, a um aspecto relevante da estrutura cognitiva do indivíduo. Isto é, nesse processo, a nova informação interage com uma estrutura de conhecimento específica, a qual Ausubel chama de" conceito subsunçor "ou, simplesmente subsunçor, existente na estrutura cognitiva de quem aprende". (MOREIRA, 1999, p.11).

Os estudos revelam que o método é o caminho mais eficaz como forma de viabilizar o estudo da ciência e validar a pesquisa rumo à sua a verdade. É através do conjunto de fatores metodológicos que conseguimos encurtar caminhos, incluir e excluir hipóteses para chegarmos às evidencias científicas. O que já foi vivenciado pelo pesquisador torna-se de fundamental importância para a evolução da pesquisa, o saber já adquirido, é a base para as novas formulações de hipóteses AUSUBEL (1978, p. 4): “(...) O fator mais importante que influencia a aprendizagem é aquilo que o aprendiz já sabe. Averigue isso e ensine-o de acordo".

Interpretando Ausubel, percebemos que ensinar significativamente requer, primordialmente, valorizar que o aluno traz como conhecimento prévio, o subsunçor, ou inseridor, como um ponto de referência, um pilar ao qual a nova informação se apoiará até que também ela própria adquira significado suficiente para se adaptar à estrutura cognitiva desse aluno.

Nota-se que a teoria da aprendizagem significativa teoria se opõe diretamente à chamada de Aprendizagem Mecânica, que denota aprendizagem de conceitos sem a ligação com conhecimentos anteriormente vivenciados na estrutura cognitiva do aluno. Na aprendizagem Mecânica, a informação se liga de maneira arbitrária na mente daquele que aprende, não havendo interação entre a nova informação e àquela anteriormente armazenada. Como exemplo típico de aprendizagem mecânica, 
podemos lembrar de quando os professores cobravam a tabuada decorada, sem a preocupação com o significado do conceito de multiplicação.

Moreira cita Ausubel (1978, p.41) quando fala de condições para ocorrência da aprendizagem significativa:

\begin{abstract}
A essência do processo de aprendizagem significativa é que as ideias simbolicamente expressas sejam, de maneira substantiva (não literal) e não arbitrária, ao que o aprendiz já sabe, ou seja, a algum aspecto de sua estrutura cognitiva especificamente relevante (isto é, um subsunçor) que pode ser, por exemplo, uma imagem, um símbolo, um conceito ou uma proposição, já significativos.
\end{abstract}

Um grande facilitador e que denota a efetividade da aprendizagem significativa reside na relação entre o conteúdo ensinado tenha correlação com a estrutura cognitiva do educando, de maneira não arbitrária e não literal. Um material com essa característica é dito potencialmente significativo (MOREIRA, 2017b).

Em uma proposta de aprendizagem baseada na interdisciplinaridade, Sommerman (2015, p. 209) propõe "os saberes das disciplinas das quatro grandes áreas do conhecimento acadêmico ciências da natureza, ciências formais, ciências sociais e humanidade”.

Para Foucault (2008), o regime imposto pelas disciplinas possui a função de evidenciar as relações do saber e do poder nas relações sociais. Segundo o autor, é como se o saber confirmasse o empoderamento dos indivíduos, de forma a criar uma hierarquia de conhecimentos em meio à sociedade.

Uma discussão devidamente epistemológica da interdisciplinaridade requer um aparte sobre o campo disciplinar.

[...] chamamos "disciplinas" a conjuntos de enunciados que tomam emprestado de modelos científicos sua organização, que tendem à coerência e à demonstratividade, que são recebidos, institucionalizados, transmitidos e às vezes ensinados como ciências [...] (FOUCAULT, 2008, p. 200)

Ferreira e Loguercio (2016) ressaltam que a crítica weberiana aponta para a predominância da racionalidade técnica na prática docente, que se personifica em pontos: clareza dos objetivos, escolha da essencialidade do saber, forma de aplicação desse saber, conteúdos e conceitos contemplados pelo currículo e critérios para avaliar a efetividade de aprendizagem. Segundo o autor, esses fatores associados podem traduzir-se em aprendizado significativo, agregando conhecimento ao estudante.

O difícil de todo o processo é como registrar a evidência da aprendizagem significativa. A aquisição de significados é o produto dessa reação química chamada aprendizagem significativa. Isto é, o significado psicológico surge quando o significado potencial (lógico) do material que é apresentado 
ao estudante transforma-se em saber cognitivo de maneira substantiva e não arbitrária, agindo com os subsunçores existentes na estrutura cognitiva que o aluno já traz consigo. Entenda-se aqui a expressão rebuscada subsunçores como pilares que o aluno já construiu através do saber ao longo de sua existência. Assim, os testes de compreensão, por exemplo, devem ser reformatados, de forma a contextualizar o conteúdo com os saberes já adquiridos pelo estudante. Deve-se propor aos alunos que identifiquem dentro da proposição de um exercício, por exemplo, os conteúdos apreendidos em sala de aula, ou até mesmo que eles façam uma correlação com o "onde" ou o "em que" este conceito aparece na sua rotina diária.

Em 1972, Joseph Novak, na universidade de Cornell, desenvolveu uma estratégia facilitadora da aprendizagem significativa, o mapeamento conceitual. Instrumento que possibilita mostrar, de maneira pontual, as relações já presentes na estrutura cognitiva de um aluno, o mapa conceitual possui a vantagem de ser, do ponto de vista construtivo, mais simples e menos trabalhoso que a elaboração de um texto.

\section{METODOLOGIA:}

Esta pesquisa foi implementada, com bases nos métodos de eficácia da aprendizagem significativa apresentados no livro: A teoria da Aprendizagem Significativa e sua implementação em sala de aula de Moreira, Marco Antonio, editora UNB (2006) proposto com base nos estudos feitos por David Ausubel e Novak.

O que se pretendeu foi aplicar os conhecimentos estudados no livro à disciplina Química, de forma a entender e tentar minimizar as causas do fracasso de um número demasiadamente grande de alunos nos estudos dessa disciplina.

A metodologia adotada foi do tipo pesquisa exploratória e consistiu no levantamento de dados, por intermédio de questionários e construção de mapas conceituais pelos alunos do terceiro ano do ensino médio do Colégio Pedro II, campus São Cristóvão III, no Rio de Janeiro. Foram estudados os casos de alunos que não obtiveram êxito nos estudos da Química durante o curso do ensino médio. Os alunos responderam a um questionário e lhes foi ensinado como construir mapas conceituais que, além de serem utilizados como recurso para análise de conteúdo, foram utilizados como negociadores de significado e facilitadores do aprendizado de Química.

De um modo geral, mapas conceituais podem ser utilizados como instrumentos de ensino e/ou aprendizagem. Além disso, podem ser utilizados como auxiliares na análise do conteúdo curricular (STEWART et al, 1979). 
A construção de mapas conceituais é uma técnica que apresenta bastante flexibilidade e gera possibilidades que permite a sua utilização de forma a fluir com o raciocínio do estudante. Em função disso, os mapas podem ser implementados em diversas situações e com as mais variadas finalidades, como: analisar a equivalência do currículo, a didática do educador e formas de avaliação (MOREIRA e BUCHWEITZ, 1993).

De maneira análoga, mapas conceituais podem ser usados para mostrar as relações significativas que existem entre conceitos ensinados em uma única aula, em uma unidade de estudo ou em um curso inteiro. São representações concisas das estruturas conceituais que estão sendo ensinadas e, como tal, provavelmente facilitam a aprendizagem dessas estruturas. Entretanto, diferentemente de outros materiais didáticos, mapas conceituais não são auto instrutivos: devem ser explicados pelo professor. Além disso, embora possam ser usados para dar uma visão geral do tema em estudo, é preferível usá-los quando os alunos já têm uma certa familiaridade com o assunto, de modo que sejam potencialmente significativos e permitam a integração, reconciliação e diferenciação de significados de conceitos (MOREIRA, 1980).

A ideia central da metodologia foi aplicar à disciplina Química os conceitos indicados em mapas conceituais. Na Figura 1 é apresentado um exemplo de mapa conceitual desenvolvido por Moreira baseado na teoria de aprendizagem significativa de Ausubel (MOREIRA e BUCHWEITZ, 1993).

Figura 1 Mapa conceitual desenvolvido na teoria de aprendizagem significativa

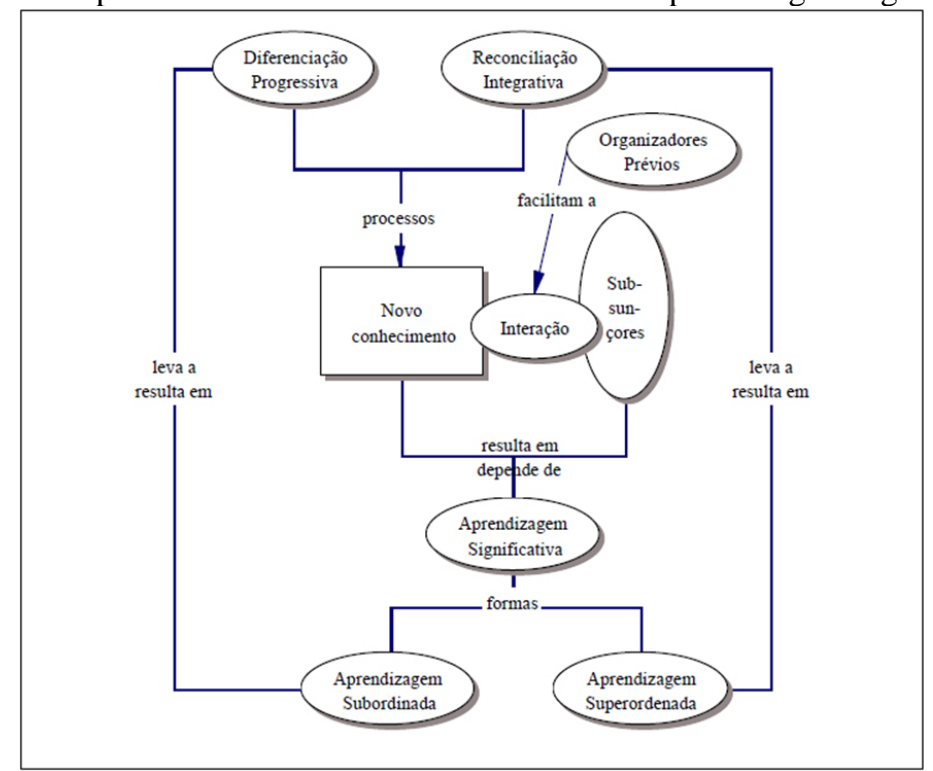

Fonte: Moreira e Buchweitz, 1993.

Aparentemente simples e às vezes confundidos com esquemas ou diagramas organizacionais, mapas conceituais são instrumentos que podem levar a profundas modificações na maneira de ensinar, 
de avaliar e de aprender. Procuram promover a aprendizagem significativa e entram em choque com técnicas voltadas para aprendizagem mecânica. Utilizá-los em toda sua potencialidade implica atribuir novos significados aos conceitos de ensino, aprendizagem e avaliação. Por isso mesmo, apesar de se encontrar trabalhos na literatura ainda nos anos setenta, até hoje o uso de mapas conceituais não se incorporou à rotina das salas de aula da Química. Mas há relatos de estudos com mapas conceituais nas mais diversas áreas e em todos os níveis de escolaridade (NOVAK E GOWIN, 1996).

\subsection{RELAÇÃO ENTRE O FRACASSO E APRENDIZAGEM SIGNIFICATIVA}

Para validar esta proposta foram realizadas pesquisas com as turmas que trabalho no Colégio Pedro II Campus São Cristóvão III, situado à Rua Campos de São Cristóvão s/n, Rio de Janeiro.

As pesquisas ocorreram nos dias em 26 de abril e 27 de agosto de 2020. Foram trabalhados alunos repetentes do primeiro e do segundo anos, cuja componente geradora do fracasso foi a Química e que estão alocados nas turmas. Os alunos foram orientados com relação aos mapas conceituais e foi solicitado a cada um que, individualmente construíssem um mapa dos assuntos que os mesmos tiveram dificuldade e que, possivelmente, os reprovou.

A proposta dessa pesquisa é baseada na Teoria de Ausubel sobre a aprendizagem significativa.

Foi esclarecido aos alunos que não havia necessidade de confecção em nenhuma folha sofisticada e que os mapas poderiam ser realizados nas folhas simples de seus próprios cadernos ou fichários. Também foi esclarecido que não havia necessidade de colocar nome e que os mapas não fariam parte de avaliação regular da disciplina.

Os alunos foram identificados com siglas em que a letra significava a turma. Assim, A = T.1109 e B = T.2210, seguido à letra, vem o número que corresponde ao registro do aluno na ficha de chamada da escola. Portanto, a sigla A-27 corresponde ao aluno de número 27 lotado na turma 2306.

Alguns alunos, surpreendentemente fizeram questão de colocar seu nome no trabalho.

\section{RESULTADOS E OBSERVAÇÕES:}

\subsection{QUADRO PROBLEMA}

Dos 27 alunos repetentes no primeiro ano, 15 foram reprovados em Química, desses 15, 11 ainda fracassaram em outras componentes curriculares.

Como podemos ver abaixo: 


\begin{tabular}{|l|l|}
\hline Identificação & Reprovado em: \\
\hline A - 01 & química e matemática \\
\hline A - 04 & química, matemática e física \\
\hline A- 05 & química \\
\hline A - 07 & química \\
\hline A - 10 & química, física, matemática e português \\
\hline A - 11 & química \\
\hline A - 13 & química \\
\hline A-14 & química, física e matemática \\
\hline A-15 & química, física e matemática \\
\hline A-19 & química e física \\
\hline A-20 & química e matemática \\
\hline A-21 & química e física \\
\hline A-23 & química e geografia \\
\hline A-26 & química, português, história, e física \\
\hline A-27 & química e matemática \\
\hline
\end{tabular}

Dos 25 alunos repetentes do segundo ano, 11 foram reprovados em Química, desses 11, 09 ainda fracassaram em outras componentes curriculares.

Como podemos ver abaixo:

\begin{tabular}{|l|l|}
\hline Identificação & Reprovado em: \\
\hline B - 01 & química e matemática \\
\hline B - 04 & química, matemática e física \\
\hline B - 05 & química e matemática \\
\hline B - 07 & química \\
\hline B - 10 & química, física, matemática e português \\
\hline B $-\mathbf{1 1}$ & química física, matemática e português \\
\hline B -13 & química e matemática \\
\hline B -14 & química, física e matemática \\
\hline B -19 & química \\
\hline A - 21 & química, matemática e física \\
\hline A - 25 & química e geografia \\
\hline
\end{tabular}

Foram construídos 27 mapas na turma 2301 e 25 na turma 2306.

Para ilustrar, estão anexados dois desses mapas. Procurei reportá-los tal qual foram feitos pelos alunos. 
Mapas conceituais construídos pelos alunos Aluno A - 07

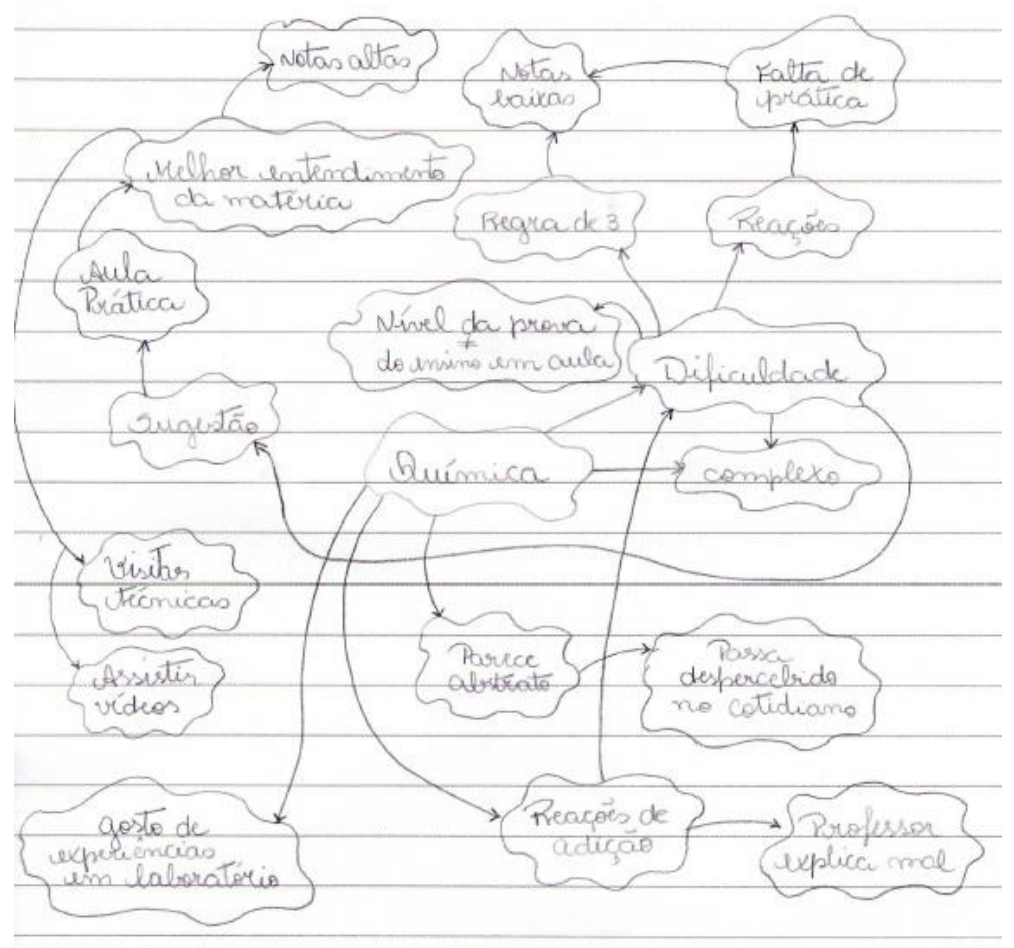

Aluno B - 19

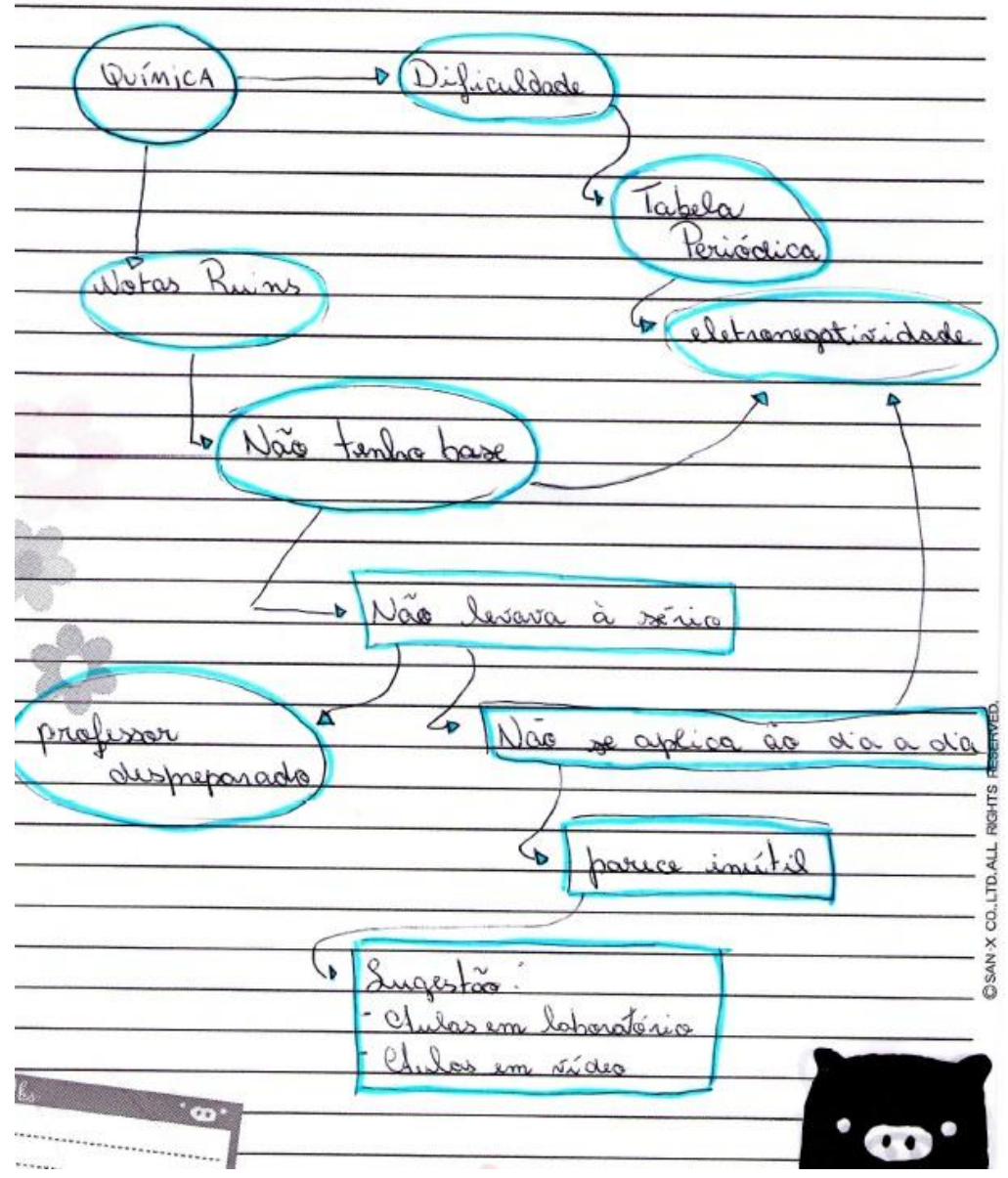


De um modo geral, percebe-se que os alunos apresentam alguns subsunçores. Principalmente quando o assunto está relacionado com as suas experiências diárias. Entretanto, os mapas revelam que muitos dos alunos não se interessam pela química, por acharem muito "decoreba" e não conseguirem estabelecer conectividade lógica entre os conceitos entre a disciplina e a realidade, para construção do mapa.

Relacionando com a teoria da aprendizagem significativa, percebe-se que mesmo com dificuldades em associar os mapas conceituais, os alunos são possuidores de alguns subsunçores relativos a determinados conteúdos, sobretudo quando se relacionam com os aspectos voltados para o seu cotidiano. Entretanto, uma grande maioria não percebe o "porquê" de aprender a Química ou não vê relação que relaciona a ciência com a sua vida cotidiana.

Entre as principais insatisfações citadas pelos alunos estão:

- Nível da prova acima do que é ministrado em sala;

- Falta de cuidado na confecção das provas;

- Dificuldades com a matemática;

- Despreparo do professor para saciar dúvidas;

- Falta de paciência do professor para com as dúvidas dos alunos;

- Falta de conectividade com a vida cotidiana do aluno;

- Conteúdos muito mecânicos;

- Excesso de regras de nomenclaturas;

- Excesso de fórmulas;

- Professor que demonstra saber, porém não sabe transmitir.

Muitas sugestões foram propostas pelos alunos para trazer mais significado à aprendizagem. Dentre as mais importantes estão:

- Aulas experimentais;

- Maior utilização do laboratório na escola;

- Visitas às indústrias;

- Menor quantidade de conteúdo por aula;

- Maior preparo didático por parte dos professores;

- Maior atenção às dúvidas dos alunos;

- Confecção de vídeo-aulas;

- Aulas interdisciplinares. 
Com relação as dificuldades percebidas nos alunos, disponibilizou-se um canal via internet e um material relativo aos conceitos mais reclamados, como cálculos estequiométricos, isomeria e classificação periódica, para auxílio às dúvidas.

\section{CONCLUSÃO:}

Os estudos baseados nos mapas conceituais demonstraram que os alunos apresentam sérias dificuldades em ver significado e traduzir os códigos da Química e têm dificuldade em associar os conteúdos estudados em sala com as coisas que o circundam em seu dia-a-dia. Foi percebida também a insegurança quanto ao uso correto de alguns conceitos básicos e fundamentais ao estudo de novos assuntos, denotando a ausência de subsunçores para construção do saber.

Os resultados obtidos com este trabalho apontam para a existência de aprendizagem significativa, quando as aulas são baseadas em fatos correlacionados ao cotidiano dos alunos.

Os resultados foram discutidos com a professora de Química da escola e ficou acertado que para os alunos com maior dificuldade, seriam usados construtores primários, chamados de "Química Zero" e que seria oferecido um horário extra para apoio aos alunos que tivessem interesse em resgatar tais conceitos. 


\section{REFERÊNCIAS BIBLIOGRÁFICAS:}

AUSUBEL, D.P. - Aquisição e retenção de conhecimentos: uma perspectiva cognitiva. Lisboa: Plátano Edições Técnicas. Tradução de The acquisition and retention of knowledge: a cognitive view. (2000). Kluwer Academic Publishers, 2003.

BACHELARD, Gaston. - A formação do espírito científico: contribuição para uma psicanálise do conhecimento - Rio de Janeiro: Editora Contraponto, 1996.

BROUSSEAU, Guy - Os diferentes papéis do professor. in: Didática da Matemática. Reflexões Psicopedagógicas - Trad. Juan Acuña Llorens. Porto Algre: Artes Médicas, 1996.

FERREIRA, M.; LOGUERCIO, R. Q. Análise de Competências em Projetos Pedagógicos de Licenciatura em Física a Distância. Revista Brasileira de Pesquisa em Educação em Ciências, v. 16, n. 2, p. 389-419, 2016.

FILHO, Olavo L.S.; FERREIRA, MARCELLO - Teorias da aprendizagem e da educação como referenciais em práticas de ensino: Ausubel e Lipman - Revista do Professor de Física • Brasília, vol. 2, n. 2, 2018.

FOUCAULT, M. A Arqueologia do Saber. Rio de Janeiro: Forense Universitária, 2008.

LEMOS, Pablo Santana e SÁ, Luciana Passos - A AVALIAÇÃO DA APRENDIZAGEM NA CONCEPÇÃO DE PROFESSORES DE QUÍMICA DO ENSINO MÉDIO. Ens. Pesqui. Educ. Ciênc. (Belo Horizonte) [online] - vol.15, n.3, p.53-71,2013.

Disponível em <http://www.scielo.br/scielo.php?script=sci_arttext\&pid=S198321172013000300053\&lng=en\&nrm=iso >. ISSN 1983-2117.

MOREIRA, M.A. - Mapas conceituais como instrumentos para promover a diferenciação conceitual progressiva e a reconciliação integrativa. Ciência e Cultura, 32(4): 474-479, 1980.

MOREIRA, M. A. - Teorias de aprendizagem. São Paulo: E. P. U., 2a Edição ampliada - 2017a, $243 p$.

MOREIRA, M. A. Grandes desafios para o ensino da física na educação contemporânea. Rev. Prof. Física, 1, 1 (2017b)

MOREIRA, M. A. - Unidades de ensino potencialmente significativas - UEPS. Internet: http://www.if.ufrgs.br/ moreira/UEPSport.pdf (Acesso em: 03/01/2018).

MOREIRA, Marco Antonio - Teoria da Aprendizagem significativa e sua implementação em sala de aula. Brasília: Editora Universidade de Brasília, 2006.

BOCK, A. M. B. - Psicologias: uma introdução ao estudo da Psicologia. São Paulo: Saraiva, 1999.

POLITO, A. \& COELHO, A. L. M. B., Referenciais teóricos na pesquisa em ensino de Física e o caso da teoria ausubeliana - Apresentado no XVII Encontro de Pesquisa em Ensino de Física - 2018.

SOMMERMAN, A. - Objeto, método e finalidade da interdisciplinaridade. In: PHILIPPI Jr., A.; FERNADES, V. (Orgs.). Práticas de interdisciplinaridade no ensino e pesquisa. Barueri: Manole, 2015. 